\title{
Running Head: In Situ Sensing of the Atmosphere by Drones
} Jason F Berry ${ }^{1,2 *}$

${ }^{1}$ Meteorologist in Charge at StormTrackerWx, LLC

${ }^{2}$ Adjunct Instructor at Taylor University in Upland, USA

\begin{abstract}
As commercial drones increase in availability, worldwide-so can the use of unmanned aerial vehicles to collect in situ data of the atmosphere. Drones are readily accessible and can reach altitudes of 1,500 feet or more. Obstacles lie within Federal Aviation Administration (FAA) stipulations, which prevent the use of recreational drones from exceeding 400 feet, or line of sight from their controller. Reasoning to use drones for meteorological research can be made, using a four-part method: The controller maintains visuals of the aircraft through an onboard video feed; aircraft location is maintained through a minimum 7 GPS satellites, drones can be easily transported in the field with Meteorologists, data can be obtained through the use of onboard sensing equipment.
\end{abstract}

Keywords: In situ; Drones and meteorology

Abbreviation: UAS: Unmanned Aircraft System; UAV's: Unmanned Aerial Vehicles

\section{Drones and Meteorology}

In Situ Sensing of the Atmosphere Drones-or Unmanned Aerial Vehicles (UAV's), are a type of aircraft without a human pilot aboard. These types of aircraft are gaining extensive popularity by hobbyists, due to their increased commercial manufacture, worldwide. Before the recreational use of drones, the United States Air Force and British Royal Air Force began using UAV's in situations, where manned flight is considered "too risky" or difficult [1]. Unlike commercial drones, Military UAV's can stay in the air for hours at a time and carry a payload of thousands of pounds. The US. Air Force's MQ-9 "Reaper" for example, has an external payload capacity of over 3,000 pounds [2].

The idea to use non-commercial drones for weather forecasting purposes gained notoriety in 2014, in an article published by Brendan Richardson of The Washington Post. The article drew attention to NASA Unmanned Aircraft System (UAS) named the "Global Hawk", capable of flying up to 30 hours at altitudes greater than 55,000 feet. In 2013, the Hawk spent several hours gathering data around Tropical Storm Nadine [3]. Richardson's article went on to cite an article by The Los Angeles Times, in which weather sensing equipment used to collect temperature, humidity and pressure could be used aboard drones weighing as much as 55 pounds $[3,4]$.

Since their commercialization in 2014, recreational use of drones was projected to increase exponentially at the beginning of 2015 . The Consumer Electronics Association predicted consumer drone sales would increase in 341,000 units sold in 2014 , by $49 \%$ [5]. This projection parallels the results of a Sky Pixel survey published in Forbes January 2015, which stated $59.68 \%$ of commercial drone owners would fly recreational, while $30 \%$ of recreational pilots surveyed said they also intend to fly for professional purposes $[5,6]$. With the increase in commercialized drones, the FAA adopted guidelines for recreational use of UAV's. The "Know before You Fly" campaign states hobby or recreational drone flights should fly below 400 feet and keep the aircraft within visual line of sight at all times [7]. However, there have been instances where recreational drone use has exceeded 1,500 feet in altitude, through the use of modified applications for smart devices. Recreational UAV flights at this altitude are considered "unsafe" for manned aircraft by FAA guidelines, which also prohibit flight within 5 miles of an airport - unless granted tower clearance [7].
Given these guidelines, the use of recreational drones by Private Meteorologist to conduct in situ analysis of the atmosphere can be safely obtained at suitable altitudes, using the following 4-part method approach: The controller maintains visuals of the aircraft through onboard video feed. The UAV used in this example for in situ flight was capable of reaching a maximum height of 500 meters from factoryin correspondence with International Civil Aviation Organization (ICAO) guidelines. Remote control of the aircraft was maintained at a frequency in the $5 \mathrm{GHz}$ spectrum-reducing "noise" common at lower frequencies. Given an "open-area" communication distance of 500-700 meters, visual flight was maintained using the manufacture's smart phone app, with a video feed of 30 frames-per-second.

Aircraft location is maintained through a minimum 7 GPS satellites. Before flight, the UAV must register a minimum of 7 Global Positioning Satellites (GPS). This ensured the aircraft recorded an accurate home-point and maintained its current location in relation to the pilot on the ground, at all times. Should signal have been lost with the controller, an auto "Return-to-Home" feature would have guided the aircraft back to within feet of its original take-off position, landing it safely.

Drones can be easily transported in the field with Meteorologists. The average wingspan of a commercial drone is $350 \mathrm{~mm}$. Fully-loaded with battery and props, the drone used for in situ flight carried a maximum weight of 1242 grams. Both the size and weight made for manageable transportation within the field.

In situ data can be obtained through the use of onboard sensing equipment. The addition of a temperature-humidity logger was attached to the take-off platform on the bottom-left of the UAV. The data logger measured approximately 4.96 inches long and 1.10 inches wide. Weighing less-than 200 grams, the addition of the data logger did

${ }^{*}$ Corresponding author: Jason F. Berry Meteorologist in Charge at StormTrackerWx, LLC, Adjunct Instructor at Taylor University in Upland, USA, Tel: +419-438-7146; E-mail: jberry@stormtrackerwx.com

Received November 15, 2015; Accepted November 30, 2015; Published December 07, 2015

Citation: Berry JF (2015) Running Head: In Situ Sensing of the Atmosphere by Drones. J Climatol Weather Forecasting 3: 143. doi:10.4172/2332-2594.1000143

Copyright: (c) 2015 Berry JF. This is an open-access article distributed under the terms of the Creative Commons Attribution License, which permits unrestricted use, distribution, and reproduction in any medium, provided the original author and source are credited. 
not negatively affect the total take-off weight of the aircraft, at just over 1240 grams. Temperature was measured within a range of -20 to 70 degrees Celsius (C), within an accuracy of $+/-0.3$ degrees $(\mathrm{C})$, Relative Humidity $(\mathrm{RH})$ was measured on a 0 to $100 \%$ range.

Total flight time lasted about 25 minutes. This fell within the manufacturer's specifications for total battery life on a full charge, although battery output was likely negatively affected by a decrease in environmental temperature with height, considering the time of year (late February). The UAV flew to the suggested manufacturer's height of 500 meters, before signaling a loss with the controller and descending in height. At $10 \%$ battery life, the aircraft returned to its home-point, before safely landing.

Once the UAV was secured, the logger was collected and data analyzed, via USB (Figure 1). Since the UAV was restricted to a maximum height of 500 meters, temperature readings were extrapolated through 2,000 feet, using the barometric formula $(\mathrm{Ph}=\mathrm{P} 0 \mathrm{e}-\mathrm{mgh} / \mathrm{kT})$, where the solution for the change from ground (P0) to height $\mathrm{h}(\mathrm{Ph})$ yields the temperature - dewpoint corresponding to 2,000 feet above mean-sea-level pressure (MSLP). The extrapolation takes into effect a perfect environmental lapse rate, where temperature decreases with height, exponentially. In an imperfect environment however, where capping inversions are likely to be present this time of year 2000 feet (77.28 millibars) represents the height where change in temperature is most likely to occur between the dry adiabatic lapse rate $(9.6 \mathrm{C} / \mathrm{km})$ and moist adiabatic lapse rate $(6 \mathrm{C} / \mathrm{km})$.

Therefore, the change in pressure depends on density, but $p$ depends on the pressure:

$\mathrm{p}=\mathrm{mP} / \mathrm{kT}$ which yields $\Delta \mathrm{P} / \Delta \mathrm{h}=-\mathrm{mgP} / \mathrm{kT}$

The integration of commercial drones with meteorology presents

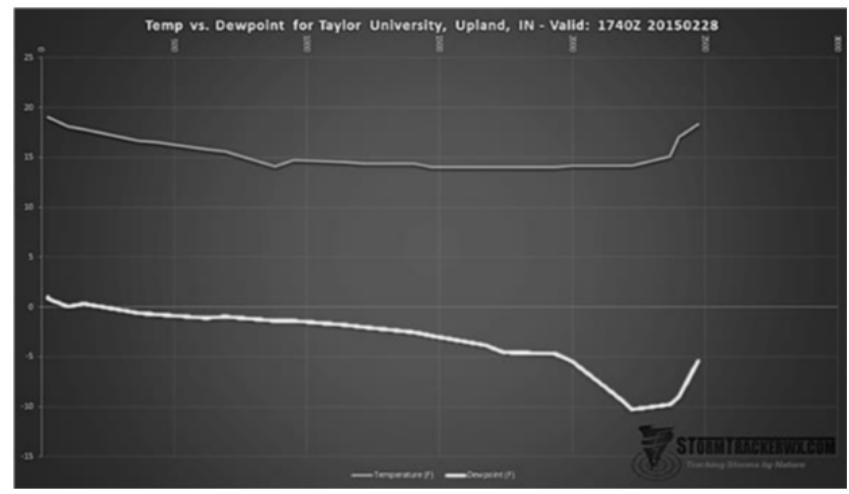

Figure 1: Line graph illustrating correlation between temperature (top) vs. dew point (bottom) in degrees Fahrenheit $(F)$; dew point calculated using the formula $\mathrm{Td}=\mathrm{T}-(100-\mathrm{RH}) / 5)$

Citation: Berry JF (2015) Running Head: In Situ Sensing of the Atmosphere by Drones. J Climatol Weather Forecasting 3: 143. doi:10.4172/2332 2594.1000143 a unique opportunity to record real-time weather data from locations otherwise reserved for commercial aircraft and weather balloons. While both the aforementioned means of obtaining atmospheric data are integral to meteorology, they have limitations as to where and when data observations can take place. Weather balloons are confined to the vertical extent of the atmosphere, whereas commercial aircraft can record data in both the vertical and horizontal realm, but are not as readily accessible in remote areas when needed.

Using UAV's, Meteorologists can easily transport commercial drones from one location to the next, while in the field. Onboard sensing equipment allows recording real-time environmental data of the atmosphere at any given time. While specific obstacles still exist, including range of flight and ability to withstand tornadic wind speedsamong other severe weather elements; the ability to extrapolate in situ data using atmospheric principles provides insight into future possibilities of using commercial drones for meteorological research and development.

\section{References}

1. Drones: What are they and how do they work? - BBC News (2012) BBC News

2. Predator RQ-1/MQ-1/MQ-9 UAV, United States of America (2015) armytechnology.com

3. Richardson B (2015) Drones could revolutionize weather forecasts, but must overcome safety Concerns.

4. Kelly D (2013) Scientists hope to predict tornadoes by using little drones.

5. CEA predicts $\$ 102.8$ million in consumer drone revenue (2015) Illustration on drone usage vs. 3D printers, according to CEA's Eye on Emerging Tech report.

6. McNeal GS (2015) Will Recreational Drone Flying Lead Drone Usage.

7. Model Aircraft Operations (2015)

OMICS International: Publication Benefits \& Features

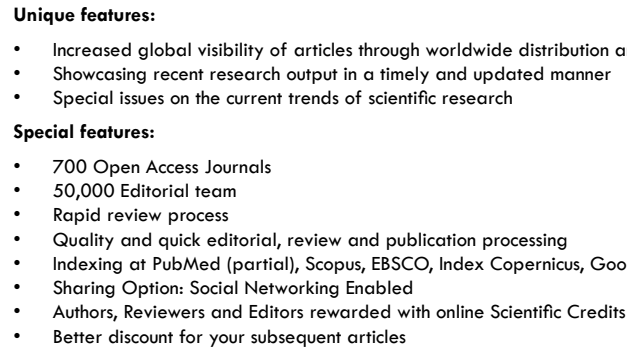

Submit your manuscript at: http://www.omicsonline.org/submission/ 